\title{
A fome como questão política
}

Frei BetTo

A

FOME, como questão política, entrou na agenda brasileira desde 1946, quando Josué de Castro publicou o clássico Geografia da fome, sublinhando que a subnutrição de milhões de pessoas nada tem a ver com a fatalidade, seja climática, seja religiosa. Porém, antes de L ula, presidente da R epública algum tomou a si o desafio de erradicar a fome, excetuando o programa de reformas de base de J oão Goulart, abortado pelo golpe militar de março de 1964.

Em 1991, o candidato Lula, derrotado na eleição presidencial anterior, incumbiu o Instituto Cidadania de elaborar um programa de segurança alimentar e nutricional para o Brasil, tarefa desempenhada por J osé G omes da Silva ( pai do ministro J osé G raziano da Silva). Segurança al imentar é um conceito que data da Primeira G uerra M undial (1914-1918) e tem a ver, sim, com segurança nacional. A soberania de uma nação corre o risco de fragilizar-se na medida em que ela não assegura à sua população alimento em quantidade e qualidade suficientes, não prevê estoques reguladores, nem medidas preventivas às calamidades naturais e vê-se obrigada a importar alimentos imprescindíveis à cesta básica.

Participei da reunião no I nstituto Cidadania, em São Paulo, na qual o G overno Paralelo de Lula lançou o programa de segurança al imentar e nutricional. $\mathrm{N} \mathrm{a}$ o casião, L ula encarregou B etinho ( $\mathrm{H}$ erbet J osé de Souza) de levar a bandeira às ruas, dando ensejo à Ação da Cidadania.

Três razões motivaram o fundador do PT a oferecer ao país um programa daquela índole: 1) 0 alarmante crescimento da miséria, agravada pela estagnação econômica dos anos de 1980 e do progressivo aumento da desigualdade social; 2) o imperativo de incluir a fome na agenda política, "desclandestinizando-a", à semelhança do que ocorreu com a escravatura: após seus 358 anos de vigência no país, ela só foi oficialmente abolida por figurar na pauta política das décadas precedentes a $1888 ; 3)$ sua origem pessoal. Ao contrário de N ilo Peçanha, único presidente do Brasil que veio da pobreza, Lula nasceu na miséria. Pobreza, como dizia D om H elder Camara, é viver do indispensável. M iséria é carecer do indispensável. A experiência da fome em sua infância marcou definitivamente o caráter do atual Presidente.

0 programa de segurança alimentar esteve presente nas três campanhas presidenciais em que Lula concorreu após a derrota de 1989 (1994, 1998 e 2002). Só em agosto de 2002 ele passou a ser conhecido pela marca Fome Zero. Em 27 de outubro de 2002, em sua primeira manifestação pública após conhecido 0 resultado que Ihe deu vitória, Lula declarou que assegurar a cada brasileiro e brasileira três refeições ao dia, ao fim de quatro anos, representaria a culminância de sua missão histórica. 
Elaborado no Instituto Cidadania por uma equipe coordenada por José G raziano da Silva, atual ministro da Segurança Alimentar e Combate à Fome, 0 Fome Zero tornou-se prioridade do governo Lula, dispondo, em 2003, de um orçamento de $\mathrm{R} \$ 1,8$ bilhão. Antes de seu lançamento oficial, em 30 de janeiro de 2003, o programa recebeu muitas críticas, al gumas pertinentes, feitas por quem entende de segurança alimentar enutricional, e outras improcedentes, de quem imaginava algo bem diferente do que estava sendo formatado pelo governo federal e implantado, como experiências-pilotos, nos municípios piauienses de Guaribas e A cauã. C riticava-se o telhado da casa quando ainda cuidávamos de assentar os alicerces.

\section{U m programa de inserção social}

A partir de dados imprecisos, calcula-se que haja no Brasil cerca de $44 \mathrm{mi}-$ Ihões de pessoas em estado de subnutrição, o que equivaleria a quase dez milhões defamílias. 0 fato éque morrem, todo ano, cerca de 180 mil crianças por subnutrição.

O M inistério Extraordinário de Segurança Alimentar e N utricional e Combate à Fome optou por iniciar o programa nos dois municípios acima citados, caraterizados pelo baixo ID H (Í ndice de D esenvolvimento H umano). Formados os $\mathrm{C}$ omitês $\mathrm{G}$ estores em cada um deles, integrados por lideranças das comunidades, passou-se a cadastrar as famílias beneficiárias, quinhentas em cada município, a partir do critério de renda per capita inferior a meio salário mínimo. 0 cadastro feito pelo governo anterior apresenta incorreções, como a ausência de famílias que nem documentos possuíam.

Ao contrário da maioria dos programas de combate à fome, o Fome Zero não é assistencialista, nem se resume a ações emergenciais. Trata-se de uma política de inserção social, para a qual, mais importante do que distribuir alimentos, é gerar renda, trabalho, resgatar a auto-estima e a cidadania. Ações emergenciais não ficam descartadas, até porque "a fome não pode esperar", alertava B etinho. o escopo do programa, porém, visa a combinar políticas locais (restaurantes populares, cozinhas comunitárias, sacolões, Bancos de Alimentos etc.); políticas específicas (cartão-alimentação, ampliação do Programa de Alimentação do Trabalhador, estoques de segurança, ampliação da merenda escolar etc.); e políticas estruturais (reforma agrária, incentivo à agricultura familiar, microcrédito etc.).

Em 2003, o Fome Zero prioriza cinco esferas: 1. municípios do semi-árido nordestino e do Vale do J equitinhonha (M G), em estado de calamidade pública; 2. acampamentos e assentamentos rurais; 3 . aldeias indígenas em estado de subnutrição; 4 . população que vive nos e dos lixões; 5 . comunidades quilombolas.

C ada família beneficiária recebe um cartão-alimentação, preferencialmente entregue à mulher, que lhe dá direito de retirar, todo mês, $R \$ 50,00$ na Caixa E conômica Federal. Com este recurso, pode-se adquirir todo tipo de alimento (estão excluídos da lista de compras as bebidas alcoólicas, refrigerantes e fumo). $\mathrm{N}$ ão se exige nota fiscal, exceto se o vendedor a emite, pois não cabe ao governo 
federal incentivar a sonegação. Pede-se apenas que o produto comprado e o vaIor pago sejam registrados numa caderneta fornecida pelo programa, de modo que se possa acompanhar a variação de preços no município e a evolução nutricional dos beneficiários ( se, por exemplo, passam a consumir verduras, legumes, frutas e mais proteína). C aso o beneficiário seja analfabeto, que se peça a alguém que registre por ele.

U ma vez de posse do cartão-alimentação, a família beneficiária passa a ser alvo de um conjunto de políticas públicas, que visam a retirá-la da exclusão social. Assim, além da documentação - da certidão de nascimento ao CPF - são oferecidos a ela cursos de alfabetização e profissionalização, construção de moradia e cisterna de captação de água da chuva (se vive no semi-árido), hortas domésticas e comunitárias, microcrédito, cooperativismo, agricultura familiar, programas de saúde etc. Até maio, seiscentos jovens e adultos tinham sido alfabetizados em Guaribas e Acauã, e 386 pessoas já haviam feito cursos de profissionalização.

O cartão-alimentação tem validade de seis meses, prorrogáveis por mais dois períodos de igual duração. Supõe-se que, ao fim de um ano e meio, estas famílias estejam produzindo renda suficiente para garantir a sua segurança alimentar e nutricional. 0 êxito do Fome Zero consiste em tornar o beneficiário, o quanto antes, livre da dependência do programa e da solidariedade da sociedade civil.

O Sede Zero complementa o Fome Zero. É politicamente incorreto falar em "combate à seca", assim como não há co mbate à neve. Trata-se de aprender a conviver com a seca, combatendo a sede. $\mathrm{N}$ esse sentido, há vinte anos um agricultor do semi-árido descobriu que não é justo culpar São Pedro pela falta de água naquela região do país. Água há, sobretudo da chuva; ocorre que a sua precipitação se concentra em poucos dias do "inverno" nordestino. Resta, pois, saber colhê-la e conservá-la. Assim, ele inventou a cisterna de placa de cimento, capaz de conter dezesseis mil litros, suficientes para abastecer uma família de cinco pessoas por oito ou nove meses. $N$ os primeiros minutos da precipitação, a chuva lava a atmosfera e o telhado da casa. Só então é aberto o cano que liga a cal ha à cisterna, filtrando folhas e gravetos. M esmo nos anos de maior seca, chove 0 bastante para enchê-la. A água colhida é utilizada para dar de beber aos animais e na higiene doméstica (banho, limpeza, cozinha etc.). A utilizada no banho e na lavagem de utensílios deve ser conservada para regar a horta ou pomar em volta da casa, desde que não seja jogada diretamente nas plantas, mas a dois ou três palmos de distância, de modo que a terra filtre os componentes químicos.

U ma cisterna custa, hoje, $R \$ 1.800,00$, já agregado o valor educativo, imprescindível para alçar a família à cidadania. Cerca de cinqüenta mil já foram construídas ao longo dos últimos vinte anos. O P1M C - Programa de 1 M ilhão de Cisternas - é monitorado pela ASA (Articulação no Semi-Árido www.asabrasil.org.br), fórum que congrega mais de setecentas entidades, entre O NGs, sindicatos, I grejas, associações etc. A ASA é, de fato, o braço hídrico do Fome Zero. 0 governo Lula descontingenciou dezessete milhões de reais que, 
somados ao compromisso assumido pela Febraban (Federação Brasileira de Bancos), de construir, este ano, dez milhões de cisternas, possibilitará que sejam abertas, até dezembro, no mínimo 22 mil cisternas.

\section{D esenho do Fome Zero}

O Fome Zero é assessorado pelo C onsea (C onsel ho de Segurança Alimentar e Nutricional), presidido pelo sindicalista L uís M arinho, integrado por 62 pessoas (treze ministros de Estado; onze observadores; 38 personalidades da sociedade civil organizada). É um órgão de caráter consultivo, diretamente vinculado à Presidência da República. A maioria de seus membros atua na área de segurança alimentar e nutricional e/ ou lida com populações carentes.

Para que o programa se estenda a todo o país, como está previsto para 2004, é preciso que cada E stado e município forme o seu respectivo Consea, de preferência manten do a proporção de dois terços representantes do Terceiro Setor e um terço representantes do poder público. A té o final de 2003, o Fome Zero chegará a mil municípios do semi-árido, bem como a lixões, aldeias indígenas, quilombos, assentamentos e acampamentos rurais. Em maio, o programa já se estendia por 193 municípios; cestas básicas emergenciais já tinham sido entregues a 113.909 famílias de 626 acampamentos rurais; 5,5 milhões de reais haviam sido repassados ao governo do $\mathrm{M}$ ato Grosso do Sul para atendimento a onze mil famílias indígenas; e, por meio da Fundação Palmares, 142 comunidades quilombolas estavam sendo atendidas. O s recursos da merenda escolar, para crianças de quatro a seis anos, subiram, per capita, de $R \$ 0,06$ para $R \$ 0,13$ por dia.

As iniciais do M inistério Extraordinário de Segurança A limentar formam a palavra M esa. Sobre esta M esa, a M obilização Social do Fome Zero, coordenada por $O$ ded Grajew e por mim, colocou Copo, Prato, SAL e Talher. Em cada município deve ser constituído, por voluntários, um Copo (Conselho O perativo do Programa Fome Zero), também conhecido por CRD (Centro de Recepção e D oação de Alimentos), que atua como braço executivo do Consea ou, na falta deste, do Comitê Gestor.

Segundo o "M anual do M utirão" (M esa, 2003) o Copo/ CRD tem como função cuidar da arrecadação de recursos no local, administrar as doações que chegam e responsabilizar-se pela armazenagem e pelo transporte dos alimentos. É ele que identifica e seleciona as entidades consideradas idôneas pelo Conselho de Assistência Social ou, na falta deste, por órgão similar, a serem atendidas. De preferência, o Copo/ CRD deve dispor de endereço eletrônico e telefones, operados por voluntários, para orientar doadores e receptores. Cabe a ele cadastrar os beneficiários, os doadores permanentes, bem como monitorar a logística da coleta e da distribuição, além de ser responsável pela fiscalização da qualidade e origem dos alimentos recebidos. N uma cidade populosa, cabem Copos setoriais, como o de uma confissão religiosa, ou de uma universidade, ou de um condomínio, ou de uma instituição pública ou privada etc. 
Prato significa Programa de Ação todos pela Fome Zero. Equivale ao comitê do Betinho. Espera-se que haja milhares deles espalhados pelo país, formados por voluntários, organizados por local de trabalho, bairros, igrejas, escolas, clubes, empresas etc. São os braços operativos do F ome Zero. O rganizam coletas e doações e, coordenados pelo Copo/ CRD, as encaminham para as entidades que trabalham com as famílias beneficiárias.

$M$ ais do que arrecadar alimentos, o programa quer arrecadar solidariedade, unindo a fome de comer com a vontade de fazer. O s Pratos devem ajudar as famílias beneficiárias a caminhar da exclusão à inclusão social; da pobreza à geração de renda; da dependência à cidadania.

Em quase todos os municípios do país, famílias carentes são acompanhadas por Agentes Comunitários de Saúde. $\mathrm{N}$ as áreas de atuação da Pastoral da C riança, mães gestantes e crianças de zero a seis anos de idade são acompanhadas por agentes voluntários. $\mathrm{H}$ á ainda agentes jovens dos $\mathrm{N}$ úcleos de A tendimento I ntegral à Família, vinculados ao M inistério de Assistência e Promoção Social.

Todos esses agentes podem ser também SAL - Agentes de Segurança Alimentar, desde que capacitados para esta função. O SAL acompanha as famílias e os núcleos populacionais beneficiados pelo Fome Zero. É seu papel saber como o beneficiário caminha da exclusão para a inclusão social: se mês a mês tem meIhorado a dieta, a higiene corporal, bucal e doméstica; se os analfabetos têm participado do curso de alfabetização; se os desempregados freqüentam o curso de profissionalização; se a família cultiva horta doméstica ou participa da horta comunitária; se desenvolve agricultura familiar; se empenha-se na construção de cisterna; se participa da formação de cooperativas etc.

Talher é um instrumento de alimentação. Para o programa, não só alimentação física, mas também mental e espiritual. 0 Fome Zero não quer saciar apenas a fome de pão, mas também a de beleza: promover a educação cidadã dos beneficiados.

A equipe conhecida por Talher prepara monitores que capacitam quem participa de Comitês Gestores, Copos, Pratos ou atua como SAL. E ajuda a multiplicar muitos Talheres pelo Brasil afora.

\section{Protagonismo da sociedade civil}

O Fome Zero depende da participação da sociedade civil (cf. "Como os voluntários podem fazer parte do Programa Fome Zero", cartilha do Faça Parte www.facaparte.org.br). D e um lado, inúmeras pessoas que doam alimentos não perecíveis, entregues aos postos de coleta nas agências da $\mathrm{C}$ aixa E conômica $\mathrm{Fe}$ deral, do Banco do Brasil, dos Correios enas unidades militares. São, ao todo, 34 mil postos de coleta, que até maio haviam recolhido 850 mil toneladas de alimentos. As doações de pequeno porte destinam-se ao município em que são coletadas, entregues a entidades (civis, religiosas etc.) que atuam junto aos segmentos mais carentes da população. 
U ma das iniciativas valorizadas pelo programa é o Banco de Alimentos, que recolhe, nos dias úteis, inclusive alimentos perecíveis, doados por padarias, açougues, restaurantes e supermercados, e os faz chegar, no mesmo dia, sob rigoroso controle sanitário, à mesa dos necessitados (asilos, creches, clínicas de pacientes pobres, população de rua etc.). 0 Banco de Alimentos da prefeitura de Santo André é modelar e capacita os interessados em desenvolver esta modalidade de serviço. O Sesc opera na mesma direção, em dimensão nacional, através do M esa Brasil, baseado nas experiências pioneiras do M esa São Paulo e M esa Rio.

As doações de grande porte, acima de dez toneladas, são destinadas aos armazéns da Conab (www.conab.gov.br) e transformadas em dinheiro ou cestas básicas entregues a quem depende de doações emergenciais, como aldeias indígenas em estado de subnutrição e acampamentos rurais. As doações em dinheiro, depositadas em contas do Banco do Brasil e da C aixa E conômica Federal, vão para o Fundo de Combate à Pobreza (www.fomezero.gov.br). Até maio, elas somavam R\$800 mil.

O Fome Zero é um mutirão idealizado pelo governo Lula e protagonizado pela sociedade civil. É significativa a parceria de entidades, instituições e empresas privadas, além das empresas públicas, todas elas envolvidas no êxito do programa, cada uma com a sua atuação específica. Há uma cartilha destinada às empresas privadas (www.ethos.org.br), orientando-as como participar do Fome Zero. Toda parceria é por quatro anos. Cada empresa é credenciada pelo programa através do N AE (N úcleo de Atendimento Especial - naeempresas@planalto.gov.br) e recebe um certificado numerado e assinado pelo ministro da Segurança Alimentar. A té maio, 240 parcerias já tinham sido oficializadas, e mais de oitocentas empresas solicitavam o direito de uso da logomarca. Como declarou o presidente Lula na reunião do Consea ( $25 / 2 / 03$ ), "é preciso criar uma consciência na sociedade de que um governo pode fazer muito, mas, por mais que o governo faça, não tem a mesma força que a sociedade terá, se ela quiser assumir para si a tarefa de cuidar disso".

\section{Avanços do Fome Zero}

Guaribas, no Piauí, tem pouco menos de cinco mil habitantes e é um dos mais pobres municípios do Brasil. Para obter água, há cinqüenta anos a população percorria $4 \mathrm{~km}$ até uma serra, onde uma gruta abriga pequena nascente. $M$ ulheres e crianças cobriam, diariamente, os $8 \mathrm{~km}$ carregando baldes na cabeça. G raças ao Fome Zero, um conjunto de caixas d'água bo mbeia a água barrenta de uma lagoa situada no perímetro urbano e, através de um chafariz, entrega à população água potável. Em outubro, cinco mil metros de rede de distribuição chegarão às casas. D ona Lídia D ias, 36 anos, contava como é bom ter água perto de casa, quando seu marido, Salvador Alves, 43, interveio: "Essa água está uma beleza. A gente só fazia filho de dia, pois minha mulher saía à $1 \mathrm{~h}$ da tarde para buscar água e só voltava às $6 \mathrm{~h}$ da manhã." 


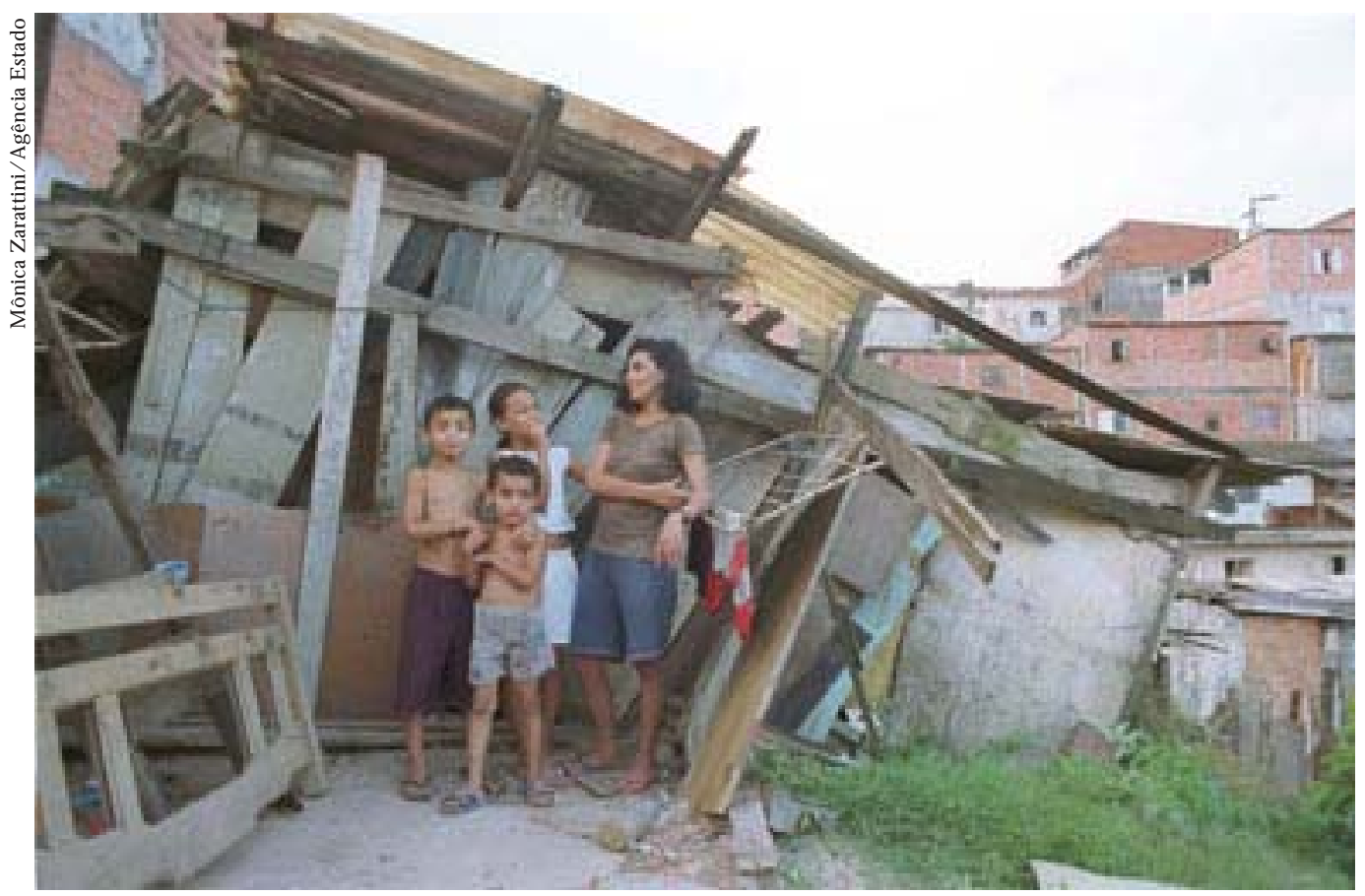

A na Lucia e seustrês filhos moram neste barraco na favela A mericanópoliş zona sul de São Paulo.

$M$ arleide Alves D uarte, 20, disse que antes do chafariz ela costumava chegar à fonte da gruta à $1 \mathrm{~h}$ da madrugada e sair dali às $7 \mathrm{~h}$ da manhã: "As mulheres faziam coivaras para aquecer os corpos. N inguém cheirava o marido, porque ele voltava do trabalho e não podia banhar-se. Agora, esses anos de sofrimento acabaram".

Guaribas colheu neste ano 160 toneladas de feijão. Pela primeira vez, ninguém negociou diretamente com os atravessadores, que ofereceram $R \$ 22$ por saca. A comunidade organizada decidiu vender coletivamente através de leilão. A saca foi vendida a preços que variaram entre $R \$ 50$ e $R \$ 70$.

Em Acauã, outro município-piloto, uma senhora de 73 anos, alfabetizada em três meses, pediu ao agente de segurança alimentar: "Q uero ir ao sindicato rural mudar minha carteira de aposentada." Ele não entendeu a razão. Ela acrescentou: "Lá tem o meu dedo. Agora quero botar minha assinatura."

A meta no Piauí era implantar, em 180 dias, dois comitês gestores. Em 120 dias são 24. D ocumentação completa, de certidão de nascimento a CPF, já foi entregue a 337 pessoas. Feiras municipais funcionam em Guaribas e Acauã, onde estão sendo construídos mercados públicos. A eletrificação levou luz a quatro povoados rurais de Guaribas. A previsão de assegurar, em 180 dias, a posse do cartão-alimentação a mil famílias foi significativamente superada: em 120 dias, 13.307 famílias de 24 municípios piauienses já podiam retirar mensalmente $\mathrm{R} \$$ 50,00 nas agências da Caixa E conômica Federal. Estão sendo construídas em Guaribas, Acauã, Alta e Vila Irmã Dulce, em Teresina, 1.500 moradias, todas com sete cômodos. Estavam previstas 430 fossas sépticas nos primeiros seis meses. Foram abertas 1.500 em quatro meses. 
$\mathrm{N}$ os dois municípios-pilotos, o A nalfabetismo Zero já favoreceu 600 adultos. O s alfabetizadores - estudantes e professores da região - ganham no final do curso, que dura três meses, $R \$ 100,00$ por aluno alfabetizado, ou seja, cerca de $\mathrm{R} \$ 1.900,00$ pelos três meses de trabalho. $\mathrm{E}$ cada alfabetizado recebe, com 0 diploma, $R \$ 200,00$, mais $R \$ 100,00$ pela carta enviada ao presidente $L$ ula e mais $R \$ 100,00$ pela carta remetida ao governador Wellington D ias. Assim, a fome de letras reativa a economia local, saciando também a de pão.

Em fevereiro, o programa "Fantástico", da TV Globo, mostrou a favela Piratininga, em $\mathrm{O}$ sasco (SP), onde vivem emigrantes de Guaribas. Risonaldo Ferreira Alves, 23, vivia ali e trabal hava como ajudante de pedreiro. Atraído pelas boas notícias do Fome Zero, retornou ao município: “Voltei porque estão ocorrendo mudanças. Guaribas não tinha nada. Não tinha calçamento, não tinha empregos. N ão dava para sobreviver." Agora, ele será empregado pela Cohab (C ooperativa $\mathrm{H}$ abitacional) do Piauí na construção de casas.

Aderismar de Andrade Dias, 20, também retornou a Guaribas, abandonando em São Paulo o trabalho com moldura de gesso, pelo qual recebia $\mathrm{R} \$$ 250,00 mensais. Agora, presta serviço à construção de casas, dirigindo o caminhão do pai, e ganha, em média, $\mathrm{R} \$ 30,00$ por dia no transporte de material. N 0 final do mês, Aderismar vai ganhar mais do que em São Paulo. "E com a vantagem - diz ele - de morar com meus pais, não ter medo da violência e não viver em favela."

A população de Guaribas reivindica também uma rádio comunitária. Além de informação, ela quer expressar a sua palavra. Palavra é sinônimo de D eus, Verbo que se fez carne. Esse resgate de cidadania propiciado pelo Fome Zero é, sem dúvida, seu maior mérito, que o define como um combate não apenas da fome, mas sobretudo da exclusão social. Como alertava Santo Tomás de Aquino: "N ão se pode exigir a prática das virtudes de quem passa fome. "O ito séculos depois deste alerta, pelo menos o governo brasileiro entendeu que sem pão não há paz. Esta, como bradou o profeta I saías há quase três mil anos, deve necessariamente ser filha da justiça. $N$ esse sentido, o Fome Zero lança também as sementes da V iolência Zero.

Saiba mais sobre o Fome Zero:

www.bancobrasil.com.br

www.caixa.gov.br

www.coepbrasil.org.br

www.mobilizacao.org.br

Central telefônica (ligação gratuita, das 8h às 20h): 0800-707-2003.

ResUmo - A SEgURAN ÇA alimentar é um conceito relacionado com a segurança nacional, uma vez que a soberania de uma nação corre o risco de fragilizar-se ao não garantir 
alimento em quantidade e qualidade suficientes à sua população. O programa Fome Zero não é assistencialista nem se resume a ações emergenciais. Trata-se de uma política de inserção social. É um mutirão idealizado pelo governo Lula e protagonizado pela sociedade civil.

ABstract - FOOD SECURITY is a concept related to national security since a nation sovereignty is jeopardized when food is not provided in quantity and quality enough for its people. The "Zero H ungry" is neither an aid program nor an emergency action. It is a policy of social includedness. I t is a task-force proposed by the L ula administration and protagonized by the civil society.

Frei Betto ( C arlosA Iber to Li ibânio C hristo) é assessor especial da Presidência da R epública e coordenador da M obilização Social do Programa Fome Zero. Frade D ominicano, tem 48 livros publicados (quinze traduzidos para outros idiomas), é jornalista, antropólogo, filósofo e teólogo. Foi consagrado intelectual do ano (1986) pela U nião Brasileira de Escrito res e homenageado pela Fundação Kreisley, de Viena, por seus trabalhos em defesa dos direitos humanos.

Texto recebido e aceito para publicação em 30 de maio de 2003. 